\title{
Introduction
}

At the time of writing (August 2020) the world is in the grip of a major pandemic. We are all living in unprecedented times, having to socially distance and unable to travel far. One of the significant effects of the pandemic has been to propel us, in Africa as everywhere elsewhere, into using digital connectivity in ways and amounts we would not have believed possible only six months ago. It seems timely, in a volume focusing on digital communication in Africa, to start off this introduction with some current, living examples of how individuals and governments are communicating virtually in Africa in these challenging times, and to discuss the priorities, difficulties and innovative practices they seem to reveal. Many of these factors were already present before the pandemic, and are reflected in the chapters of this book, which were written before the world went into lockdown. We asked the contributors to the volume, as well as the current Chair and Secretary of the Language in Africa Special Interest Group, British Association of Applied Linguistics, which provided the inspiration for the project, to send us some 'snapshots' of how digital communication is currently being used to fight the pandemic and support citizens in their African contexts. The comments are of course personal but made by keen and qualified observers.

Their snapshots reveal how longstanding problems, such as language choice, persist in new modes of digital communication, how the pandemic has highlighted the digital divide between rich and poor in the same country, but also how the pandemic is forcing change and development. Some African countries seem to be quite well connected already, and importantly there is a willingness on the part of the government to improve digital connectivity. The government in Nigeria seems to have reacted very similarly to the global North in terms of desired and ambitious measures, although the infrastructure is not totally up to the task. However, local inventiveness and creativity are evident. Abdulmalik Ofemile emailed the following:

'The pandemic has forced people and policy makers in Nigeria to emphasise digital communication in tertiary education, government, commerce and personal interaction.

The Minister of Education directed that all tertiary institutions should start delivering lectures online. The academic staff replied that he has 
not provided the required infrastructure to make full scale online teaching a reality that is effective in the institutions. They pointed out that power outages, inadequate hardware, lack of trained personnel, classrooms/lecture hall that are not designed to align with online teaching and learning, lack of digital libraries to support learning, and expensive broadband costs inhibit online education. In addition, the majority of students do not have digital devices and adequate digital literacy to enable them attend lectures effectively. However, the government and some private organisations are now organising lessons for primary and secondary school students in various subjects that are presented on television, radio and some locally produced interactive web-based learning management systems as well as Zoom.

The President and state governors now hold council meetings with their executive committees using digital devices and online platforms.

Business is getting more digitised. For example, banks and other utility service providers are rolling out more online platforms to enable consumers carry out transactions from the comfort of their homes/offices without meeting physically. This ensures that social distancing is not violated.

Due to the lockdown and restriction on movement across the country, family members who are stranded in different parts of the country communicate using digital devices and platforms such as smart phones, tablets and computers using WhatsApp, Facebook Messenger and WeChat to make voice and video calls as well as sending text messages. Furthermore, awareness regarding Covid-19 is propagated more through digital devices, content and platforms by government, groups and individuals.

On the whole, communication among Nigerians is becoming profoundly digital at all levels however, a lot of work still needs to be done to bring this up to the accepted standards. In addition, the pandemic provides huge opportunities for multidisciplinary knowledge and skill development to enhance digital communication in Nigeria.

As for as how languages are being used in digital communication in the pandemic, for official interaction, the President, Governors and most government officials are using English in official communications. Their official Twitter handles all communicate in English too. However, during the pandemic, government officials such as the Presidential Task Force on Covid-19 now give out information using English, Hausa, Igbo, Yoruba and Nigerian Pidgin during press conferences when journalists and other members of the audience ask questions in these languages. For education, all lessons and learning materials provided for all categories of learners online, on tv and radio are presented in English except for teaching other languages. Radio and tv stations now use multilingual anchor systems for Covid-19 programmes. They also have similar multilingual social media teams to handle online communication which often co-occurs with live programmes. The lockdown has led to a remarkable increase in online chat groups on WhatsApp, Facebook etc as well as the use of Zoom for personal interaction. 
The language of communication on these platforms is not strictly regulated and is a matter of personal choice. So members use multilingual strategies to communicate'.

\section{Multilingual Practices}

It is interesting that in Abdulmalik's observations, formal online instruction for learners appears to be focused on English, in contrast to the multilingual practices in other forms of digital communication. Leketi Makalela has also noticed this phenomenon in South Africa, where home schooling has been taking place:

'The (learning) materials are in English when the majority of the parents are themselves not proficient in English. The need for African languages was apparent, but no resources were available during the pandemic crisis. Absence of indigenous African languages for learning and teaching and by extension to online resources is the case in point why students are not coping so far with online learning and why parents are not able to engage with online content for their children'.

However, Epimaque Niyibizi has noticed a more multilingual approach:

'At the University of Rwanda, where I teach, we are now holding faculty virtual meetings using Zoom, WebEx and Microsoft Teams; our students are studying from home using e-learning platforms, radio and $T V$; and I have to say that social media like WhatsApp are now being used by students not only to exchange chats and information, but to exchange learning materials as well. You find that every unit/department has created a WhatsApp group for easy and quick communication.

On the aspect of mixing languages in such digital communication, it is also a frequent practice. We use four official languages in Rwanda, namely Kinyarwanda, English, French and Kiswahili, and they are used in various fora, but with frequent mixing of those languages, particularly on social media'.

These comments resonate with a major theme in our chapters :

- How does digital communication support the multilingual practices of Africans (or not)? For example, In the case of Nigeria and South Africa, multilingual practices do not seem to be happening in education online, but does seem to be taking place on social media, in official and personal communication and for disseminating information about Covid 19.

\section{Social and Political Change}

A number of our contributors have noted how digital communication has linked the diaspora to those living in a particular African country, often with a politically subversive or corrective effect. For example, 
Seraphin Kamden, the current Chair of the Language in Africa SIG, makes the point that the pandemic has encouraged close communication between the diaspora and those living in Cameroon, with the diaspora providing accurate information and negating the effects of false news:

'Going from the point of digital communications as including social media information and the digital online tools and platforms such as WhatsApp and Facebook, I would say that the Covid-19 pandemic has brought much more importance to mobile technologies and phone communications between rural Africa and the African diaspora in Europe, but has also helped fill an information gap: between established local media networks trapped in political propaganda and hidden corporate advertising and diasporic Africans who have access to some more up-todate information about the Covid-19 pandemic and who try their best to feed back that useful medical information to their families back in Africa. Again, this pandemic has created a new landscape in digital communications in terms of a new layer of data and information flows that somehow does bypass the traditional and government-controlled channels-something unimaginable just three decades ago where political propaganda and any useful information were mostly generated by state-controlled media, and most of it on local press and radios and TV networks'.

Sarah Ogbay reports much the same phenomenon for Eritrea, where households are not allowed access to the internet, and where individuals can theoretically only receive information via state controlled television and media. However ordinary people (if they can afford it) are accessing information by phone from relatives in the diaspora and TV channels from outside Eritrea via satellite dish. Similarly, Abdulmalik Ofemile observes for Nigeria that:

'One other trend emerging is that Nigerians in the diaspora are using online media to hold the government to account for the handling of Covid-19 and other issues as well as make meaningful contributions for improvement. Nigerian interest/pressure groups in the diaspora are using digital media, particularly Zoom, to organise virtual interactive town hall meetings with Ministers and government officials. Participants ask government officials questions on pressing issues while government officials provide answers. Nigerians in the diaspora also pass on their experiences in their host countries as well as relevant professional input to the government officials. These meetings are held using English but you still see some use of Nigerian pidgin and a sprinkling of Nigerian languages during interaction.'

These comments echo another theme in the volume, which addresses the question:

- How does digital communication put African countries in contact with ideas and influences from the wider world, and what effects might this have? As we have seen from the above examples, information flows 
and political practices are being affected by the ease of digital connections with the outside world, a trend which some of the chapters in this book were already researching before the pandemic, but which has perhaps become more marked in the current global emergency.

\section{African Languages and Culture}

On a rather brighter note, Susanna Sacks has noted a blossoming of the arts in the digital sphere in Africa during the lockdown:

'My sense is that the pandemic has focused and concentrated energy towards digital networks and communities. I haven't come across anyone doing anything totally new (yet!), but what I have seen is all energy turn towards the digital. Because more people are online for more of the day, this focus has paid off, with more engagement and faster turnarounds than usual. I have a sense this might indicate a major shift in how poetry and the arts are shared, especially as workshop-style projects are being published open source online. A sort of bright spot in this terrible time. The work I've come across has largely been promoted in English, but the performances themselves vary in language a great deal.

So, for example, Afrolit Sans Frontieres are running a virtual literary festival featuring African writers in French, English and Portuguese. In Harare, Zimbabwe, The Book Café has been sharing their '\#Lockdown sessions' on Facebook. In a further example in South Africa, the poet and playwright Siphokazi Jonas is organizing a \#slam4urlife digital poetry slam on Instagram”.

These comments reflect the third theme which is addressed by many of the contributors to this volume:

- How does digital technology help maintain African languages and cultures?

The final theme of this book encompasses all the others:

- How does digital technology provide new ways of recording and researching language use and change?

The ways in which the chapters this volume focus on these four themes are outlined below.

\section{How does digital communication support the multilingual practices of Africans (or not)?}

Although we have problematised the situation in institutionalised online education, in the informal digital platforms described in this book, people move seamlessly, naturally and easily between languages, and there is no expectation that sites such as the Facebook groups described by ResCue and Agbozo or the WhatsApp groups described in Niyibizi 
et al.'s paper should use one language only. All languages are equal in such spaces, replacing a situation where some languages, often colonial ones, exert more power. Makalela has a uniquely African and innovative take on the multilingual communication which is facilitated in digital spaces, defining it as different from code switching or translanguaging but instead characterising it as Ubuntu translanguaging, a communicative practice where input and output are exchanged in different languages to signal that one language is incomplete without the other. Makalela and Niyibizi et al. describe the positive effects of this multilingual translanguaging, which boosts social cohesion, encourages freedom of expression and generates a sense of community and togetherness.

\section{How does digital communication put African countries in contact with ideas and influences from the wider world, and what effects might this have?}

As Castells (2015) points out, digital technology can disrupt traditional power structures. It does this by facilitating the creation of autonomous spaces which are beyond the control of governments and corporations who usually monopolise channels of communication. In these freer spaces, participants can grow and develop because they are given agency. They can also communicate on a global level, receiving ideas and input from far flung places and people. Ogbay and White argue that the Facebook group they have researched, which was created by Eritrean women refugees in the diaspora, helps the members to become both politically active and more aware of their rights as women. Norton writes about the ways in which digital communication has made education a more democratic process, enabling learners themselves to both access and contribute to global knowledge production. She is interested in the extent to which identities shift as language learners and teachers engage with digital technology in diverse African communities. Her chapter contains a powerful description of The African Storybook project, whose main goal is to promote mother tongue literacy. It provides over 1000 illustrated open-access digital children's stories with over 5000 translations, in over 170 African languages, as well as the official languages of English, French and Portuguese. Users can read, download, translate, adapt and create stories for local use, using a range of mobile devices. She notes how the project developed the digital skills and social power of both teachers and learners, and enabled them to develop new identities as poets, writers, trainers and global citizens. Sacks has researched a What App group in Malawi who write, share and critique poetry, creating new postcolonial poetic forms of expression. Because they operate in a digital space, the group are not reliant on western or African publishing houses for the dissemination of their work, giving them freedom of expression about topics which might otherwise be censored. 


\section{How does digital technology help maintain African languages and cultures?}

Social media are providing a powerful way of maintaining African languages, of encouraging people to use them in communication, and of ensuring their vitality and transmission to the next generation of speakers. This also means that the important cultural concepts and customs embodied in a particular language are passed on. ResCue and Agbozo describe the creativeness of Ewe users on Facebook in improvising new lexis and orthography to communicate and represent their culture. Rowan illustrates how the use of digital technology is a much better and more holistic way compared with traditional print methods for documenting the multilingual and sociocultural contexts in which endangered languages such as Nubian are used. She also shows how digital technology empowers the language users themselves, rather than foreign 'experts', to keep records through smartphones, and how technology connects the diaspora of Nubian speakers, enabling Nubian to remain a living language.

\section{Digital technology provides new ways of recording and researching language use and change}

The chapters in this book all consider some aspect of the ways in which languages in an African context are being influenced and changed by digital communication. Digital communication provides new spaces in which language use and language rules are freer and more fluid; communicating one's message is more important than whether one adheres to conventional notions of correctness which may apply in some nondigital contexts. We've noted already that language mixing or translanguaging is a common feature of digital communication in African contexts. Crystal (2006) has pointed out that the language of digital communication merges written and spoken genres, creates neologisms and makes use of visual and spatial possibilities of meaning making. Many of the chapters in this book (for example, ResCue \& Agbozo and Ogbay \& White), describe how images, photos, video, emoticons and other visual affordances combine with words to produce complex layers of connotation, emotional expression and cultural reference. These analyses require new research methodologies. For example, taking as his starting point the fact that there is an increasing use of software agents in learning contexts, and therefore a need to understand how these agents interact with learners, Ofemile has found an innovative methodology for researching visual information. He analyses data recording spontaneous facial actions and uses it to understand patterns of listenership behaviour for Nigerian L2 English speakers taking instructions from L1 Englishmode devices. 
xviii Rethinking Language Use in Digital Africa

\section{Organisation of this Book}

We have organised the chapters of the book around these four themes multilingual practices, linguistic and cultural maintenance, the effects of communication outside Africa and language change - while bearing in mind that the reader will find that the themes are often echoed by different contributors over the entire book.

\section{References}

Castells, M. (2015) Networks of Outrage and Hope: Social Movements in the Internet Age. Cambridge: Polity Press.

Crystal, D. (2006) Language and the Internet (2nd edn). New York: Cambridge University Press. 